LICENÇA CC BY:

Artigo distribuído sob os termos

Creative Commons, permite uso e distribuição irrestrita em qualquer meio desde que o autor credite a fonte original.

\title{
A PESQUISA DOCUMENTAL NAS INVESTIGAÇÕES DE POLÍTICAS EDUCACIONAIS: POTENCIALIDADES E LIMITES
}

DOCUMENTARY RESEARCH IN STUDIES ON EDUCATIONAL POLICY: POSSIBILITIES AND LIMITS LA INVESTIGACIÓN DOCUMENTAL EN LAS INVESTIGACIONES DE POLÍTICAS EDUCACIONALES: POTENCIALIDADES Y LÍMITES

\section{Altair Alberto Fávero ${ }^{1}$} Junior Bufon Centenaro 2

${ }^{1}$ Doutor em Educação pela UFRGS. Docente do Programa de Pós-Graduação em Educação da Universidade Federal de Passo Fundo (UPF), Passo Fundo, RS, Brasil.

${ }^{2}$ Mestre em Educação pela Universidade Federal de Passo Fundo (UPF),

Passo Fundo, RS, Brasil.

\begin{abstract}
Resumo: $O$ artigo tem por escopo investigar as potencialidades e os limites da pesquisa documental ao se tratar desse tipo de instrumento metodológico em políticas educacionais. A partir de revisão de literatura de caráter exploratório hermenêutico sobre o tema, organizamos o ensaio da seguinte forma: i) inicialmente abordaremos a polissemia do conceito 'pesquisa documental', que produz ainda fortes discussões e divergências sobre a terminologia mais adequada a ser utilizada; ii) em seguida conceituaremos o objeto da pesquisa documental, para iii) estabelecer apontamentos específicos sobre o trabalho com documentos de política educacional; iv) na sequência apontaremos aspectos epistemológicos e teóricos intrínsecos à pesquisa com documentos, e por fim, v) indicaremos algumas notas conclusivas destacando potencialidades e limites do trabalho com fontes documentais.
\end{abstract}

Palavras-chave: Investigação Documental; Epistemologia das Políticas; Pesquisa Qualitativa.

Abstract: The article aims to investigate the possibilities and limitations of documentary research when dealing with this type of methodological instrument in educational policies. Based on a literature review of an exploratory hermeneutic nature on the theme, this essay was organized as follows: i) first, it addresses the polysemy of the concept of 'documentary research', which still produces strong discussions and disagreements as to the most appropriate terminology to be used; ii) next, it conceptualizes the object of documentary research, and arising from this, iii) it establishes specific aspects of work with educational policy documents; iv) it points out some epistemological and theoretical aspects intrinsic to research with documents, and finally, v) it gives some concluding remarks highlighting the potential and limits of work with documentary sources.

Keywords: Documentary Research; Policy Epistemology; Qualitative Research. 
Resumen: El artículo tiene por objeto investigar las potencialidades y los límites de la investigación documental al tratarse de este tipo de instrumento metodológico en políticas educativas. A partir de la revisión de literatura de carácter exploratorio hermenéutico sobre el tema, organizamos el ensayo de la siguiente forma: i) inicialmente abordaremos la polisemia del concepto de investigación documental, que produce todavía fuertes discusiones y divergencias sobre la terminología más adecuada a ser utilizada; ii) luego conceptualizamos el objeto de la investigación documental, para iii) establecer apuntes específicos sobre el trabajo con documentos de política educativa; iv) en la secuencia apuntaremos aspectos epistemológicos y teóricos intrínsecos a la investigación con documentos, y por último, v) indicamos algunas notas conclusivas destacando potencialidades y límites del trabajo con fuentes documentales.

Palabras clave: Investigación Documental; Epistemología de las Políticas; Búsqueda Cualitativa.

\section{Introdução}

O crescente número de documentos de política educacional nas últimas décadas tem indicado a importância da pesquisa documental como instrumento imprescindível para conhecer, descrever, caracterizar, analisar e produzir sínteses de objetos de pesquisa específicos das políticas direcionadas à educação. O presente estudo se insere na dinâmica de buscar compreender a pesquisa documental no horizonte da pesquisa qualitativa. Segundo Esteban (2010, p. 193), "Os pesquisadores qualitativos abordam fundamentalmente questões relacionadas às ações e não aos atos", ou seja, o foco da pesquisa educacional de modo geral é a "interpretação do significado de ações humanas e sociais".

O objetivo deste ensaio é destacar potencialidades e limites da pesquisa documental ao se tratar desse tipo de instrumento metodológico em políticas educacionais. Algumas indagações mobilizam nosso trabalho, a partir das quais buscaremos construí-lo: o que caracteriza uma pesquisa documental? Quais os objetos da pesquisa documental? Que peculiaridades podem ser elencadas sobre a pesquisa documental no trabalho específico em políticas educacionais? Que aspectos epistemológicos e teóricos sustentam e dão corpo a este instrumento de pesquisa? Como ocorrem as relações entre o pesquisador, os documentos e as teorias na análise documental?

Ancorados nestas indagações, buscamos uma reflexão, tendo como base a produção do campo da pesquisa em educação, por meio de pesquisa bibliográfica, amparada no método analítico hermenêutico, que problematiza os elementos técnicos, metodológicos e epistemológicos inerentes à pesquisa documental em políticas educacionais. O campo de pesquisa em políticas educacionais caracteriza-se por estar em construção, em busca da definição de sua abrangência, suas fronteiras e, logicamente, seus métodos e epistemologias singulares. Desta forma, compreendemos que a pesquisa documental consiste num dos principais instrumentos investigativos para a compreensão das políticas e, por essa razão, a necessidade de discutir suas potencialidades e seus limites. 


\section{Definição de pesquisa documental: a polissemia do} conceito

Alguns questionamentos preliminares são importantes antes mesmo de buscar definições e explicações sobre o conceito em questão. "Os pesquisadores realizam pesquisa documental ou realizam análise documental? Ou seria uma técnica de pesquisa com documentos?" (SÁ-SILVA, ALMEIDA e GUINDANI, 2009, p. 3). Na literatura especializada, encontramos diversas terminologias, não havendo um consenso em torno de como denominar: técnica, pesquisa, método ou análise documental? Cellard (2008, p. 298) utiliza tanto análise documental (no título de seu artigo) como pesquisa documental (no corpo do artigo): "Uma pessoa que deseje empreender uma pesquisa documental deve, com objetivo de construir um corpus satisfatório, esgotar todas as pistas capazes de lhe fornecer informações interessantes". Para Helder (2006, p. 1), "a técnica documental vale-se de documentos originais, que ainda não receberam tratamento analítico por nenhum autor".

Lüdke e André (2015 p. 45) afirmam que "a análise documental busca identificar informações factuais nos documentos a partir de questões ou hipóteses de interesse" e por isso perguntam pela definição de análise documental, mas também pela melhor forma de utilizar a técnica, sendo assim, falam em análise e técnica documental. Posto isso, por não haver consenso em torno de uma definição, existem diversas possibilidades de nomear o trabalho com documentos. Apesar disso, o processo de investigação documental, como expõem Sá-Silva, Almeida e Guindani (2009, p. 4), pode levar a uma definição terminológica mais plausível:

Quando um pesquisador utiliza documentos objetivando extrair deles informações, ele o faz investigando, examinando, usando técnicas apropriadas para seu manuseio e análise; segue etapas e procedimentos; organiza informações a serem categorizadas e posteriormente analisadas; por fim, elabora sínteses, ou seja, na realidade, as ações dos investigadores - cujos objetos são documentos - estão impregnadas de aspectos metodológicos, técnicos e analíticos.

Sendo assim, a pesquisa documental é compreendida como um processo que se utiliza de métodos e técnicas para a apreensão, compressão e análise de documentos dos mais variados tipos. Essa caracterização se aproxima dos estudos de Pimentel (2001, p. 179), que aborda a análise documental primeiramente como um "processo de investigação" e posteriormente destaca que ela requer "instrumentos e meios". Como "processo", evoca a noção de percurso e de metodologia e como "instrumentos e meios", remete aos procedimentos técnicos necessários à pesquisa documental. Embora haja uma polissemia conceitual em torno das investigações com documentos, o presente ensaio assume como ponto de partida a noção de num procedimento metodológico que se utiliza de técnicas e instrumentos para apreensão, compreensão e análise de documentos. Dessa forma, empregaremos as expressões "pesquisa" e "análise" documental, pois entendemos que, sob este ponto de vista, estaremos incluindo, concomitantemente, as dimensões metodológica, técnica e epistemológica da pesquisa com documentos. 


\section{Objeto da pesquisa documental: pluralidade de interpretações}

Estabelecida uma concepção terminológica comum, partimos para o objeto principal da pesquisa documental, o próprio "documento". É importante ressaltarmos que há diversos entendimentos a respeito do que são propriamente os documentos e, além disso, diferentes concepções sobre como trabalhar com eles. Os estudos de Cellard (2008) e Sá-Silva, Almeida e Guindani (2009) problematizam duas concepções principais no que tange ao entendimento acerca de documentos: uma objetiva e outra globalizante.

\section{Abordagem objetiva}

Numa perspectiva mais ligada à História, Cellard (2008) menciona a incapacidade humana de memorizar tudo e, consequentemente, os lapsos, as distorções e as alterações que ocorrem nas lembranças gravadas na memória. Os documentos são fundamentais para a memória histórica dos processos sociais,

Por possibilitar realizar alguns tipos de reconstrução, o documento escrito constitui, portanto, uma fonte extremamente preciosa para todo pesquisador nas ciências sociais. Ele é, evidentemente distante, pois não é raro que ele represente a quase totalidade dos vestígios da atividade humana em determinadas épocas. Além disso, muito frequentemente, ele permanece como o único testemunho de atividades particulares ocorridas num passado recente (CELLARD, 2008, p. 295).

Corriqueiramente, ao escutarmos a expressão "documento", tendemos a pensar em papéis oficiais, registrados, que visam comprovar algo. Tal concepção não é por acaso, pois paira ainda em nossas mentes a noção positivista do documento oficial como o único verdadeiro e passível de proporcionar uma pesquisa confiável e objetiva, em outras palavras, segura e válida. Estamos dizendo com isso que essa visão ou noção de documento é muito estreita, porque existem variadas formas de documentos, sejam oficiais ou não, que podem ser pesquisadas e analisadas. Segundo Cellard (2008, p. 296), até o final do século XIX, "a noção de documento se aplicava quase exclusivamente ao texto, e, particularmente, aos arquivos oficiais". Assim, os historiadores positivistas valorizaram o documento como garantia de objetividade, excluindo a noção de intencionalidade contida na ação estudada e na do pesquisador (SÁ-SILVA; ALMEIDA e GUINDANI, 2009, p. 7). O documento era entendido como o conhecimento histórico em si, com status científico que se impunha ao pesquisador, que tinha como função captar o real do documento, a verdade que ele tinha a revelar. Esse pensamento considerava apenas documentos oficiais, os governamentais de ações do estado e de personalidades, desconsiderando uma gama muito grande de documentos tidos como não oficias, porém com muitos elementos a pesquisar e analisar. 


\section{Abordagem globalizante}

A própria evolução da disciplina histórica reconsiderou profundamente a noção de documento. Para Cellard, a Escola de Anais ${ }^{1}$ revolucionou ao trazer uma abordagem mais globalizante acerca do que seria tido como documento ou fonte documental: "a história social ampliou consideravelmente a noção de documento. De fato, tudo o que é vestígio do passado, tudo o que serve de testemunho, é considerado como documento ou fonte" (CELLARD, 2008, p. 296). Nesse sentido, podemos citar textos escritos, documentos iconográficos, cinematográficos, objetos do cotidiano, elementos folclóricos, músicas, etc. "No limite, poder-se-ia até qualificar de 'documento' um relatório de entrevista, ou anotações feitas durante uma observação" (CELLARD, 2008, p. 297).

De acordo com o autor, os documentos podem ser classificados e divididos em públicos e privados. Os arquivos públicos são geralmente volumosos e organizados segundo ordens de classificação e, apesar do caráter público, nem sempre estão acessíveis. São exemplos de arquivos públicos: os arquivos governamentais (federais, regionais, escolares ou municipais), os do estado civil, assim como alguns arquivos jurídicos. Os documentos públicos não arquivados incluem revistas, jornais, periódicos, anúncios, circulares, boletins, que possuem um caráter de distribuição (CELLARD, 2008, p. 297).

Os arquivos privados, embora não pertençam ao domínio público, também passam por processos de arquivamento sob a guarda de um depósito, com uma classificação e um tratamento concernente à conservação. Estão incluídos nesse grupo os documentos de organizações políticas, de sindicatos, Igrejas, comunidades religiosas, instituições, empresas, etc. Por fim, ainda na esfera dos documentos privados, encontramos os pessoais, como exemplo, as autobiografias, os diários, as cartas, as histórias de vida e os documentos familiares (CELLARD, 2008, p. 298).

\section{Aspectos epistemológicos e teóricos da pesquisa documental em políticas educacionais}

As definições de pesquisa documental e de seu objeto, realizadas anteriormente, fazem parte, em grande medida, do domínio da pesquisa da disciplina histórica. É compreensível que encontremos, entre os historiadores, uma produção maior sobre este procedimento metodológico, pois as fontes documentais embasam o trabalho do historiador na tentativa de buscar reconstruções do passado, da história humana, dos processos sociais. Em nosso caso, nos compete questionar sobre o papel da pesquisa e da análise documental em política educacional, pois é uma área da pesquisa em educação que trabalha diretamente com documentos de política. Dessa forma, abordaremos em seguida apontamentos específicos sobre a análise documental em políticas educacionais. 
Com base na definição de que a pesquisa documental é um procedimento metodológico que se utiliza de técnicas e instrumentos para apreensão, compreensão e análise de documentos, temos como objetivo, no presente tópico, situar elementos próprios da pesquisa documental em políticas educacionais, para salientarmos a relevância dessa modalidade investigativa para uma área de pesquisa em franca expansão. Isto posto, é importante perguntarmos: quais são as principais fontes documentais em políticas educacionais? Como ocorre a relação pesquisador/documento/teoria nesse modo de fazer pesquisa documental? Que peculiaridades são características dos textos e dos documentos de política educacional? Quais os cuidados necessários para que seja possível "decifrar" documentos para compreender a política educacional? Perante esses questionamentos, descreveremos inicialmente os tipos de fontes e documentos, para caracterizar em seguida a relação pesquisador/documento/teoria e, por fim, as peculiaridades que envolvem o "decifrar" documentos de política educacional. Para tanto, teremos como referência as investigações de Shiroma, Campos e Garcia (2005), Mainardes (2006), Esteban (2010), Lüdke e André (2015) e Evangelista (2012).

\section{Documentos de política educacional}

Geralmente, os documentos mais pesquisados em políticas educacionais são encontrados em formato eletrônico ou em papel. São materiais em grande medida oficiais e oficiosos. Estes, por sua vez, significam que mesmo não tendo caráter oficial, são produzidos por órgãos ou são oriundos de fontes governamentais. Para Evangelista (2012, p. 52), esses materiais advêm "do aparelho de Estado, de organizações multilaterais e de agências e intelectuais que gravitam em sua órbita". A autora elenca também uma lista de documentos que são característicos de política educacional: leis, documentos oficiais e oficiosos, dados estatísticos, documentos escolares, correspondências, livros de registros, regulamentos, relatórios, livros, textos e correlatos. Como já observamos anteriormente, com base em Cellard (2008, p. 297), um documento pode ser qualquer tipo de registro histórico (fotos, músicas, arte, entrevistas, depoimentos, jornais, filmes, etc.), que estrutura a base empírica da pesquisa. Em concordância com Evangelista (2012, p. 52), destacamos que esses documentos servem como base empírica para a pesquisa em políticas educacionais na medida em que estão relacionados com a difusão de diretrizes políticas para a educação, sendo frequentemente analisados como fontes primárias.

\section{Relação pesquisador/documento/teoria}

A reconstrução conceitual que realizamos sobre a pesquisa documental numa dimensão qualitativa, globalizante e holística, possui suas origens na corrente historiográfica da escola de Anais, estando, portanto, permeada por uma perspectiva 
epistemológica e por um campo teórico. Segundo Esteban (2010), como perspectiva epistemológica, a análise documental regida por um viés globalizante está ligada ao Construcionismo. "A Epistemologia Construcionista rejeita a ideia de que existe uma verdade objetiva esperando ser descoberta. A verdade, o significado, emerge a partir de nossa interação com a realidade", em outras palavras, "o significado não se descobre, mas se constrói" (ESTEBAN, 2010, p. 51).

Para Esteban (2010), uma perspectiva epistemológica abriga em si campos teóricos, tradições de pensamento, que também podem conter em si outras correntes teóricas. A análise documental situa-se no campo teórico conhecido como "Interpretativismo" e flerta com duas correntes bem específicas deste campo, a hermenêutica de validação e o interacionismo simbólico. Segundo a autora, na hermenêutica de validação existe a "possibilidade de capturar os significados dos textos (observações, entrevistas, jornais, cartas...) e o significado que uma pessoa atribui a suas experiências. Existem significados imutáveis e inalteráveis que são objetivo de toda interpretação" (ESTEBAN, 2010, p. 64). Isso quer dizer que os documentos possuem algo de objetivo a revelar, que independe da significação do pesquisador, e por outro lado, pelo interacionismo simbólico, o pesquisador deve situar-se dentro do processo de definição, vendo o mundo a partir do ponto de vista do corpo documental que estuda: "devemos ser capazes de tomar o lugar de outros. Esta tomada de papel é uma interação. É uma interação simbólica porque só é possível para os 'símbolos significativos', isto é, a linguagem e outras ferramentas simbólicas" (ESTEBAN, 2010, p. 67).

Lüdke e André (2015, p. 5), ao problematizarem as abordagens qualitativas na pesquisa em educação, indicam que "os fatos, os dados não se revelam gratuita e diretamente aos olhos do pesquisador. Nem este os enfrenta desarmado de todos os seus princípios e pressuposições". Não há, portanto, para estas autoras, a "possibilidade de se estabelecer uma separação nítida e asséptica entre o pesquisador e o que ele estuda e também os resultados do que ele estuda". O pesquisador não se encontra em posição de neutralidade científica, como indicava o método positivista, porque ele está implicado nos documentos, nos fatos, nos fenômenos e nas consequências do conhecimento que ajudou a estabelecer.

Uma herança bastante forte da ciência positivista é o conceito de causalidade que predominou por muito tempo nas investigações no campo da educação, apontando que haveria uma linearidade entre as variáveis, e estas deveriam ser fragmentadas em suas menores partes, para que fosse possível compreendê-las. Lüdkee André(2015, p. 6) ponderam que, "em vez da ação de uma variável independente, o que ocorre em educação é, em geral, a múltipla ação de inúmeras variáveis agindo e interagindo ao mesmo tempo". Quanto maior o isolamento e a fragmentação das variáveis, o enfoque do estudo fica reduzido, impossibilitando a compreensão geral de um documento em sua dinâmica complexidade.

Desses estudos - Lüdke e André (2015), Esteban (2010) -, é possível inferir que a pesquisa documental envolve interação entre pesquisador e objeto, construção de significado e de conhecimento. $O$ sujeito que investiga possui uma posição própria, o 
objeto pesquisado (documento de política) também possui sua determinação, contudo essas posições não são estáticas, são, muito antes, uma relação que é permeada pela teoria. A relação pesquisador/documento/teoria que verificamos nestas autoras também está presente nos estudos de Evangelista (2012).

Para Evangelista (2012, p. 56), a empiria como algo que é gestado na história e é manifestação da consciência humana, podendo ser conhecida pelo sujeito histórico, que ao conhecê-la acessa a própria consciência do homem. "Pelo seu conhecimento é possível articular outras formas de consciência" que expressam vida, conflitos, interesses, projetos econômicos e políticos, no limite, a própria história. Evangelista afirma que "na efervescência dessas determinações se encontram pesquisador, documento e teoria" (2012, p. 56). Dessa maneira, podemos situar uma posição do pesquisador, outra do documento e ainda o posicionamento da teoria.

A posição do pesquisador na pesquisa documental em políticas educacionais sendo uma pesquisa qualitativa possui intencionalidade. $O$ documento como algo externo ao pesquisador exige uma postura ativa deste, pois "localiza, seleciona, lê, relê, sistematiza, analisa evidências que apresenta" (EVANGELISTA, 2012, p. 56). O pesquisador vai até o documento com intencionalidades ao selecionar seu objeto, com marcas teóricas e ideológicas em si, que são determinações e dificilmente ele conseguirá livrarse completamente delas para fazer uma análise puramente objetiva de um documento. Exigir neutralidade plena do pesquisador com relação ao seu objeto de pesquisa é algo sobre-humano, diga-se, quase "angelical". Assim como o sujeito possui determinações, a fonte estudada também possui graus de objetividade, ou seja, elementos inscritos que precisam ser coletados tal qual se apresentam aos olhos do sujeito. Entretanto, conforme ressalta Evangelista (2012, p.57), "a perspectiva teórica do sujeito pode diferenciar-se daquela da fonte estudada, posto que ambas são datadas e posicionadas socialmente e sofrem objetivações específicas pelo que deve-se evitar confundir a sua existência com a do documento em exame". É necessário que haja "vigilância metodológica do sujeito sobre si e sua relação com o tema e fontes de pesquisa. Documentos oferecem pistas, sinais, vestígios e compreender os significados históricos dos materiais encontrados é sua tarefa" (EVANGELISTA, 2012, p. 57). Isso implica ao pesquisador compreender sua posição com relação à história de si mesmo, à história de sua fonte ou documento e sobre a história da produção que faz na pesquisa documental.

O conhecimento presente na documentação de política educacional não está fornecido de antemão, muito pelo contrário, o conhecimento é construído a partir da organização e da ordenação dos elementos fornecidos pelas evidências empíricas. $O$ posicionamento do sujeito pesquisador é essencial para a produção de conhecimento sobre o tema pesquisado. Sendo assim,

Trata-se do papel posto para os intelectuais: encontrar o sentido dos documentos e com eles construir conhecimentos que permitam não apenas o entendimento da fonte, mas dos projetos históricos ali 
presentes e das perspectivas que - não raro obliteradas no texto - estão em litígio e em disputa pelo conceito, pelo que define o mundo, pelo que constitui a história. Podemos afirmar que trabalhar com documentos significa aceder à história, à consciência do homem e às suas possibilidades de transformação (EVANGELISTA, 2012, p. 57).

A posição da fonte ou do documento também é importante, pois carrega uma objetividade típica que lhe é impregnada pelo momento histórico em que é gestado. Essas determinações históricas não estão dadas facilmente na fonte em si. Para chegar a elas é preciso reflexão e inquirição para buscar uma aproximação dos elementos que compõem o corpo documental que está sendo analisado. Ao se tratar de fontes primárias em política educacional, os cuidados precisam estar redobrados, haja vista que os documentos em mãos do pesquisador são incompletos e imperfeitos, além de limitados. Para Evangelista (2012, p. 59)

As fontes primárias trazem as marcas da sua produção original, de seu tempo de produção, de sua história. É necessário, então, captar as múltiplas determinações da fonte e da realidade que a produz; significa dizer captar os projetos litigantes e os interesses que os constituem, que tampouco serão percebidos em todos os seus elementos.

Pelo movimento da pesquisa, pelo processo reflexivo realizado com os dados produzidos a partir dos documentos e do conhecimento conjuntural em que um documento foi redigido é que poderemos captar as determinações históricas empreendidas na fonte pesquisada, que não oferece de forma imediata esses conhecimentos e informações.

A teoria, por sua vez, cumpre um papel determinante na relação pesquisador/ documento, pois ela exerce uma mediação. A existência da fonte para o sujeito que pesquisa depende do ato de pensar deste último, ele entra em relação de reflexão e diálogo com ela. A forma particular de pensamento do sujeito, sua teoria, seu aparato de ideias e conceitos mediarão o procedimento da análise documental. As categorias de pensamento são mobilizadas para a compreensão do tema de estudo e não para seu encarceramento empirista ou idealista, pois não existe uma concepção teórica intocável para acoplar a empiria, ao contrário, a teoria deve estar aberta para favorecer o pensar e o repensar a empiria, as fontes, os documentos, e para repor-se a si própria como instrumento de intelecção (EVANGELISTA, 2012). Isso leva a deduzir que o real (nesse caso um documento de política educacional) não deve ser encaixado numa teoria, e nem podemos intencionar que o documento apresente por si só a verdade. O que é necessário assegurar no procedimento da pesquisa documental é a relação teoria-empiria e as condições dessa relação, porque o sujeito intervém nessa relação e produz as condições de entendimento da realidade e de sua transformação. Desse ponto de vista,

\footnotetext{
O método é absolutamente fundamental, pois implica uma determinada forma de tratar, analisar, contrapor, desconstruir ou construir uma interpretação dos documentos e, por essa via, dar acesso às várias "realidades" que incorpora. É essencial considerar a maior ou menor capacidade da teorização de dar conta de suas múltiplas determinações (EVANGELISTA, 2012, p. 64).
}

Em síntese, pressupondo que os documentos não são neutros e nem inocentes, que a teoria é uma possibilidade aberta que dialoga com a empiria, com o real, com o documento, 
transformando-o e transformando-se a si mesma, não é possível então, ao sujeito, evadirse da relação: pesquisador/documento/teoria. Da mesma forma, impõe-se nessa relação a necessidade de um exercício de decifrar os documentos de política educacional.

\section{Decifrar textos de políticas educacionais}

Em vista da complexidade de componentes presentes nos documentos de política educacional, ao realizarmos uma análise documental, como já destacamos, não basta apenas pretender encontrar tudo nos "ditos" que ele contém. Shiroma, Campos e Garcia (2005, p. 428) apontam para a situação de que nos últimos vinte anos ocorreu uma "proliferação de documentos referentes à reforma educacional" e isto tem mobilizado "pesquisadores das diferentes subáreas da Educação a se debruçarem sobre o tema, com o intuito de compreender tanto o conteúdo da reforma quanto os mecanismos envolvidos na difusão da mesma". Nesse viés, para Evangelista (2012, p. 62),

Ao se tratar de política é preciso ter clareza de que eles não expõem as "verdadeiras" intenções de seus autores e nem a "realidade". Como fontes de concepções, permitem captar a racionalidade da política, desde que adequadamente interrogados. A interrogação metódica desse tipo de evidência procura apreender suas incoerências, seus paradoxos, seus argumentos cínicos ou pouco razoáveis.

O ato de "capturar" as pistas oferecidas auxilia a entender o movimento histórico, as ideias mestras das diretrizes educacionais de um determinado tempo e conduz a investigação das origens, das tendências, das influências e das ressignificações envolvidas na elaboração dos documentos. Há que termos a perspicácia de questionar a aparência das fontes, de modo especial os conceitos que elas trazem. Elas possuem muito mais elementos daqueles ditos textualmente. Os não ditos, ou seja, aquilo que é silenciado num documento ou fonte poderá ser mais importante daquilo que é proclamado. Eis aí um grande desafio do documento que se posiciona como algo enredado e complexo: buscar com profundidade o que está dito e o que não está. Segundo Evangelista (2012, p. 61), "Ler nas entrelinhas parece recomendação supérflua, entretanto, deve-se perguntarIhe o que oculta e por que oculta: fazer sangrar a fonte".

As transformações ocorridas nos discursos das publicações nacionais e internacionais sobre política educacional permitem compreender uma tentativa de unificar o sentido de conceitos e palavras. Para os autores, no início dos anos de 1990, "predominaram os argumentos em prol da qualidade, competitividade, produtividade, eficiência, e eficácia"; no findar da mesma década, percebeu-se "uma guinada do viés explicitamente economicista para uma face mais humanitária na política educacional [...] pela crescente ênfase nos conceitos de justiça, equidade, coesão social, inclusão, emporwerment, oportunidade e segurança (SHIROMA, CAMPOS e GARCIA, 2005, p. 428). Essa busca por unificação ou hegemonia discursiva estabeleceu-se com as: 
Reformas educacionais desencadeadas nos Estados Unidos e Inglaterra com a publicação dos relatórios The Paideia Proposal (ADLER, 1982) e A Nation at Risk (1983) [pois] forneceram as bases para a avalanche de reformas verificadas em vários países nas últimas décadas (APPLE, 1995). Nessa empreitada, tiveram marcada influência os organismos multilaterais como Banco Mundial (BM), Organização das Nações Unidas para a Educação, a Ciência e a Cultura (UNESCO), Organização para a Cooperação e Desenvolvimento Econômico (OCDE), Programa das Nações Unidas para o Desenvolvimento (PNUD), entre outros, que por meio de seus documentos não apenas prescreviam as orientações a serem adotadas, mas também produziam o discurso "justificador" das reformas que, preparadas em outros contextos, necessitavam erigir consensos locais para sua implementação (SHIROMA et al., 2005, p. 430).

As palavras não são postas por acaso nos documentos, elas importam e fazem a diferença. A pesquisa deve estar atenta a esse pressuposto, pois não poderemos realizar uma satisfatória análise documental sem dar atenção à linguagem utilizada. Os países têm orientado seus documentos nacionais amparados pelas diretrizes de órgãos internacionais, que por sua vez buscam construir uma "hegemonia discursiva". A transferência dos "termos" das organizações multilaterais para os documentos de política de cada país ou região não é de todo tranquila, pois implementar as orientações internacionais exige que sejam traduzidas, interpretadas e adaptadas de acordo com os jogos e interesses políticos do campo educacional de cada país. De certo modo, esse exercício faz com que os responsáveis locais pela formulação das políticas educacionais reescrevam as prescrições dadas pelos documentos internacionais. Sendo assim, não é tarefa simples para o pesquisador compreender a racionalidade que está sendo informada pelo documento, em virtude das contradições, das contingências e das influências que levam às traduções, às reescritas e às elaborações dos documentos nacionais a partir dos internacionais.

O ciclo de políticas também pode ser um guia bastante sugestivo para o trabalho com documentos de políticas, pois permite pensar o documento em seu sentido globalizante, amplo e multifacetado. Mainardes (2006) apresenta uma breve caracterização da abordagem do "ciclo de políticas", proposta inicialmente pelos pensadores ingleses Stephen Ball e Richard Bowe (1992), para uma análise geral da evolução das políticas educacionais, que se constituem por três contextos principais: contexto de influência, contexto da produção do texto e contexto da prática. Se pudéssemos localizar o documento nesses contextos, poderíamos situá-lo no segundo contexto, que é o da produção dos textos, apesar disso, estas etapas não são lineares e sequenciais, e o documento está nessa rede de contextos, e é nessa relação que deve ser compreendido.

O contexto de influência caracteriza-se como espaço de iniciação das políticas públicas e da construção dos discursos políticos, que recebem caracterizações dos interesses dos grupos que disputam influências na definição dos objetivos da educação e do significado do que é ser educado. Para Mainardes (2006, p. 97), "atuam nesse contexto as redes sociais dentro e em torno de partidos políticos, do governo e do processo legislativo. É também nesse contexto que os conceitos adquirem legitimidade e formam um discurso de base para a política". Existem também outras arenas de disputas formais, a saber, os grupos e as comissões representativas que articulam interesses e influências na origem das discussões sobre as políticas públicas voltadas para a educação. 
No contexto da produção dos textos e dos documentos de política educacional, diferentemente do contexto de influência em que estão explícitos os interesses ideológicos, apresentam-se textos políticos articulados em uma linguagem do interesse do público geral (MAINARDES, 2006, p. 97). Os documentos representam a política de formas variadas: textos oficiais, pronunciamentos, vídeos, declarações, relatórios, etc. Estes textos resultam de acordos e disputas entre os grupos, que posteriormente também disputarão o controle daquilo que o texto representa na prática. Segundo Mainardes (2006, p. 97), "políticas são intervenções textuais, mas elas também carregam limitações materiais e possibilidades", e as respostas aos documentos de política educacional implicam consequências concretas. Assim ganha espaço o terceiro contexto, que é o da prática.

Mainardes destaca a distinção feita por Ball entre "política como texto" e "política como discurso", dentro do contexto da prática:

\begin{abstract}
O processo de formulação dos textos políticos sofre muitas influências e agendas - e apenas algumas delas serão reconhecidas como legítimas e incorporadas nos textos. Os textos políticos são o resultado de disputas e compromissos. A política enquanto discurso enfatiza os limites do próprio discurso. As políticas podem tornar-se "regimes de verdade" (Foucault) na qual apenas algumas vozes são consideradas como legítimas. Política como texto e política como discurso são noções complexas porque os textos não são apenas o que eles parecem ser em sua superfície e os discursos, numa concepção foucaultiana, não são independentes de história, poder e interesses (MAINARDES, 2006, p. 97, grifos nossos).
\end{abstract}

O contexto da prática apresenta-se bastante instável, e não é por acaso, pois muitos discursos, ao enfatizar conceitos e palavras específicas, omitem outros termos intencionalmente. Com relação a isso, Shiroma, Campos e Garcia (2005, p 439) afirmam que analisar os discursos oriundos dos documentos de política educacional "funciona como um dispositivo de interpretação para colocar o dito em relação ao não dito, o que o sujeito diz em um lugar com o que é dito em outro lugar". Da mesma forma, ajuda a decifrar o que é dito de um modo com o que é dito de outro modo, para ouvir, "naquilo que o sujeito diz, aquilo que ele não diz mas que constitui igualmente os sentidos de suas palavras".

Esse exercício interpretativo e recreativo é típico do contexto da prática, pois os textos políticos estão sujeitos a interpretações diferenciadas pelos sujeitos que procuram colocar em prática as diretrizes dos textos. Dessa forma, as políticas educacionais não são simplesmente implementadas, porque na prática as ações ocorrem a partir de interpretações das políticas, o que permite a recriação, as mudanças e as transformações da política original.

A abordagem do ciclo de políticas contribui substancialmente ao trabalho com documentos de políticas educacionais, haja vista que existe muito a se descobrir em um documento, assim como é possível produzir conhecimento sobre ele. Essa produção sobre o documento depende do sujeito pesquisador e sua complexa relação com o objeto e com a teoria. Diante disso, consideramos muito pertinente a apresentada por Evangelista (2012, p. 65):

Pesquisador e semeador se assemelham: devem conhecer o campo e sua fecundidade; devem conhecer os instrumentos que lhes permitirão retirar do campo suas possibilidades de fecundação; 
devem conhecer as sementes que semearão e quando; devem pensar sobre o que será possível colher nessas condições; devem colher os frutos da terra quando for o momento propício; devem saber que o que colheram é uma das possibilidades inscritas objetivamente naquela terra e que só suas intervenções intencionais permitiram tal colheita. E disso não abrirá mão, como não abrirá mão de ter consciência em relação aos limites históricos impostos a si e à própria pesquisa.

\section{Considerações finais: potencialidades e limites da pesquisa documental}

No decorrer do presente ensaio, buscamos indicar os alcances e também as fragilidades inerentes ao procedimento metodológico da análise documental. Porém, ainda é preciso destacar alguns elementos. Os documentos de política educacional são fontes importantes de onde surgem evidências que fundamentam os pressupostos e as afirmações do sujeito pesquisador. Além disso, fornecem informações sobre determinados contextos, que se não fosse pelas fontes documentais, não haveria como conhecer. Os custos para quem se aventura numa análise documental são em geral baixos. Como destacam Lüdke e André (2015, p.45), "seu uso requer apenas investimento de tempo e atenção por parte do pesquisador para selecionar e analisar os mais relevantes". Os documentos permitem obter dados quando é impossível chegar ao sujeito (em caso de morte por exemplo), ou quando a interação com os sujeitos não é benéfica para eles e nem para a pesquisa.

Sá-Silva, Almeida e Guindani (2009, p. 13) ponderam que a pesquisa documental, dependendo do objeto de estudo e seus objetivos, "pode caracterizar-se como principal caminho de concretização da investigação ou se constituir como instrumento metodológico complementar". Nessa mesma direção, Lüdke e André (2015, p. 46) sinalizam que, como uma "técnica exploratória, a análise documental indica problemas que devem ser bem mais explorados através de outros métodos. Além disso ela pode complementar as informações obtidas por outras técnicas de coleta".

Entre as limitações do trabalho com documentos está a crítica sobre a pouca representatividade que um documento tem sobre os fenômenos que queremos analisar. "Por exemplo, estudar o que ocorre no dia a dia das escolas. Em geral as escolas não mantêm registro das suas atividades, das experiências feitas e dos resultados obtidos" (LÜDKE e ANDRÉ, 2015, p. 47). A existência de materiais aleatórios e pouco sequenciais leva a pensar que determinados documentos não representam o fenômeno a ser pesquisado. Os defensores de uma perspectiva objetivista, no entender de Lüdke e André (2015, p. 47), criticam o trabalho com documentos por ser difícil validá-los, pela falta de objetividade. Estes desconsideram em grande medida a influência da subjetividade no conhecimento científico.

Outra limitação apontada é com relação às escolhas arbitrárias dos pesquisadores, que optam por temas e enfoques de seu interesse ao analisar documentos. Isso tornaria a pesquisa documental algo difícil de validar. Porém, ressaltamos que é característico da 
pesquisa documental inferir sobre os documentos, levando-se em consideração valores, sentimentos, intenções, ideologias das fontes documentais. Além disso, retomando Evangelista (2012), podemos notar que pesquisador, documentos e teoria possuem posicionamentos e determinações e elas fazem parte da busca pela construção do significado da pesquisa documental. Por isso, a pesquisa documental ficaria enfraquecida se estivesse orientada apenas por um viés objetivista.

A pesquisa documental, como procedimento metodológico que se utiliza de técnicas e instrumentos para apreensão, compreensão e análise de documentos, é de grande valia para as investigações em políticas educacionais. Sua importância e sua qualidade vão depender da maneira como for conduzido o processo de pesquisa. Observando a complexidade envolvida nos documentos de políticas, certamente a pesquisa documental nessa área produzirá inferências e conhecimentos pautados numa perspectiva qualitativa e globalizante, atenta a critérios de plausibilidade e validação que darão confiança e credibilidade aos conhecimentos produzidos.

\section{Referências}

BACELLAR, C. Fontes documentais: uso e mau uso dos arquivos. In: PINSKI, C. (Org.). Fontes históricas. São Paulo: Contexto, 2005. p.23-80.

CELLARD, A. A análise documental. In: POUPART, J. et al. (Orgs.) A pesquisa qualitativa: enfoques epistemológicos e metodológicos. Petrópolis: Vozes, 2008.

ESTEBAN, M. P. S. Pesquisa qualitativa em Educação: fundamentos e tradições. Trad. Miguel Cabrera. Porto Alegre: AMGH, 2010.

EVANGELISTA, O. Apontamentos para o trabalho com documentos de política educacional. In: ARAÚJO, R. M. L.; RODRIGUES, D. S. (Orgs.). A pesquisa em trabalho, educação e políticas educacionais. 1ed. Campinas, SP: Alínea, 2012, v. 1, p. 52-71.

HELDER, R. R. Como fazer análise documental. Porto, Universidade de Algarve, 2006.

LÜDKE, M.; ANDRÉ, M. E. D. A. Pesquisa em Educação: abordagens qualitativas. 2. ed. São Paulo: EPU, 2015.

MAINARDES, J. A abordagem do ciclo de políticas e suas contribuições para a análise da trajetória de políticas educacionais. Atos de Pesquisa em Educação, Blumenau, v. 1, n. 2, p. 94-105, mai./ago. 2006.

PIMENTEL, A. O método da análise documental: seu uso numa pesquisa histórica. Cadernos de Pesquisa, n.114, p. 179-195, nov. 2001.

SÁ-SILVA, J. R.; ALMEIDA, C. D. de; GUINDANI, J. F. Pesquisa documental: pistas teóricas e metodológicas. Revista Brasileira de História \& Ciências Sociais, Ano I, n. I, jul. 2009.

SHIROMA, E. O.; CAMPOS, R. F.; GARCIA, R. Decifrar textos para compreender a política: subsídios teórico-metodológicos para análise de documento. Perspectiva, Florianópolis, v. 23, n. 2, p. 427-446, jul./dez. 2005. 


\section{Contato para correspondência:}

Altair Alberto Fávero.E-mail: altairfavero@gmail.com

\section{Notas}

1 Também conhecida como Escola dos Annales, foi um movimento no campo da História, surgido na França, do século XX. Os pensadores desta corrente procuraram uma forma alternativa de investigar a história fora dos determinismos e simplismos positivistas, permitindo uma análise mais conjuntural dos fatos históricos, quebrando com uma certa lógica em que os eventos históricos foram sempre tidos como lineares. 